\title{
A2AD CONCEPT IN THE MODERN SECURITY ENVIRONMENT
}

\author{
Ionuț Alin CÎRDEI \\ “Nicolae Bălcescu” Land Forces Academy, Sibiu, Romania \\ cirdei_alin@yahoo.com
}

\begin{abstract}
In the 21st century, the international scene witnesses major changes in the security environment. There are many actions aimed at redefining spheres of influence and reaffirming states as great powers. The international scene is dominated by two entities that were antagonistic during the Cold War: Russia and NATO. In recent years, Russia is trying to impose itself again as a global actor and is therefore trying to consolidate its power in Europe and the world, both by reforming its armed forces and by participating in various conflicts in the hot zones of the world.

Russia perceives NATO as its main adversary, which is trying to get closer to its vital space, reduce its spheres of influence and isolate it. As a reaction, Russia initiated a series of complex actions aimed at both maintaining buffer zones and banning access and limiting NATO's freedom of movement in the immediate vicinity of its borders. To this end, Russia has developed a series of capabilities to prevent the opponent from entering a certain area and to reduce or even forbid him any freedom of action once he has entered the area, this approach of Russia being part of the A2AD (Anti-access, Area Denial) policy..
\end{abstract}

\section{Keywords: anti-access, area denial, NATO, Russia, security.}

\section{Introduction}

Every state in the world is interested in creating the optimal conditions for achieving and maintaining national security. Nowadays, when the expansion of the phenomenon of globalization has made the problem of security dependent on many factors of economic, social, political, military nature, etc. and when modern technologies play an increasingly important role, the issue of ensuring national security is becoming increasingly important. More than that, "the proliferation of new risks and threats augments the insecurity aspects of the global environment"[1]. Because no state can isolate itself or remain neutral, each has to find the right approach, according to its position on the international scene, its possibilities and ambitions. Many states address the issue of national security from the point of view of ensuring collective security, which means shared effort, resource efficiency and greater discouragement.

Other states, especially the major global powers or regional powers that seek to maintain international status or affirmation on the international scene, address the issue of security in an individual way, with the emphasis on creating strategic advantages over the main competitors. Regardless of the situation, of the way of approaching security, it was found that the state of security can not be obtained and maintained without investing in the military field, without developing a strong military component of security. Given that modern technology makes weapons systems more and more powerful, more accurate and capable of striking long range targets, states 
are investing in creating and developing defense capabilities against military threats and creating a defensive bubble near the national territory, and around strategic objectives within which to discover, engage and annihilate any military means, whether it be long-range missiles, recconnaissance, bombing or fighter aviation, or maritime ships. As a result of this concern, the concept of strategic defense has emerged, which has as its center the idea of banning the opponent's access to certain areas and limiting his freedom of action, a concept known as anti-access, area denial (A2AD) and developed especially by the great powers, such as the US, Russia, China, who are disputing their supremacy in certain areas over which they want to maintain control as strong as possible.

\section{Content of the A2AD concept}

Freedom of action is essential to achieving success in any military action, and this must be achieved and reinforced from the very first phase of a conflict, especially in our days, when multidimensional joint actions have become a rule and when any adversary tries to guarantee superiority in the whole spectrum of military actions.

Prohibiting access and limiting freedom of action is an extremely effective approach as it can have a major impact on the opponent both physically and mentally as it discourages hostile actions due to the large number of losses that they may suffer in the near- deployment in the operation area, due to the difficulty of gaining air superiority and the psychological impact that the high level of loss could have on both the army and the population.

The A2AD concept is a particularly complex concept, evolving with the evolution of technology, which allows the surveillance of extended areas and the timely intervention in those areas. The attention of States operating this concept focuses on two distinct and complementary activities: the prohibition of the opponent's access to the areas of strategic interest and the limitation of the opponent's freedom of action once he has entered these areas.

According to the experts, the anti-access dimension (A2) refers to the actions and capabilities, usually long-range, designed to prohibit the access of an adverse force in an area of operations, mainly by engaging his aerial and nanal means and while the denial area component (AD) refers to actions and capabilities, usually short-range, designed to limit the maximum freedom of action [2]. The two activities do not necessarily involve the use of different capabilities but the integration of these capabilities and their synergic use. Developing these capabilities does not guarantee complete, total defense and security of those areas but exponentially increases the risk to the potential attacker and increases his losses to a level considered too high in the context of a small-scale conflict. In the case of a total war, in which the stake is the defeat at any cost to the opponent, these systems have limited effectiveness, depending on the level of losses assumed by the attacker and available means of attack. In our opinion, A2AD capabilities have an important deterrent role, but a limited impact on a attacker willing and capable of taking considerable risks and accepting high losses.

Developing A2AD capabilities involves building an integrated, multi-layered system that includes forces and means capable of discovering and hitting targets from as longer distances as possible in all environments, including cyber domain. The integrated system could be composed of high-precision, long-range impact systems, advanced air defense systems, anti-ship capabilities in the seaside area, artillery systems and long-range missiles, as well as other capabilities placed on sea, submarine or aerial platforms. From this range of forces and means, we must not exclude nuclear weapons, considered to be "ultimate weapons" but fortunately available to a small number of states. Creating and maintaining these capabilities involves 
significant human and material efforts, but it can provide a significant advantage over an adversary who is not prepared or willing to accept the costs of a total, high intensity and long-lasting conflict.

On the other hand, no matter how complex and solid the A2AD system is, it can be overcome and can create and then strengthen an asymmetry that allows for continued operations, airspace control and ground support.

Freedom of action after entering the theater may be limited by means focused on AD and which may be of a variety of ways: striking systems, conventional forces, explosive devices, obstacles, traps, etc. In order to maximize the effect on the opponent, the capabilities to prohibit access (A2) must be correlated and supplemented with the capabilities that limit or forbid freedom of action (AD), but this is not mandatory, as there are situations when an opponent has no significant opportunities in the A2 domain, but can carry out effective actions in the field of $\mathrm{AD}$ in both physical and cybernetic environments.

Taking into account the development of these strategies, the development of new technologies and the analysis of recent conflicts, such as the first and second wars in Iraq, the NATO intervention in Yugoslavia, etc., we can state that in the first phases of a conflict the intensity of the military actions will be very high, the pace of actions will be sustained, the consumption of resources will be very high, and the risks assumed will be proportionate, because the future success of the armed forces depends on the way of achieving the objectives in this phase. Antagonist parties will either seek to ban the opponent's access to the area of operations and protect strategic systems, or destroy enemy's capabilities and defense capabilities and guarantee freedom of action for forces to be deployed on the ground. Actions will be characterized by increased modularity, agility, and flexibility across the functions of war and will be focused on the "integration of intelligence and operations and a renewed emphasis on deception, stealth and ambiguity to complicate enemy calculations" [3], by combining all elements of combat power, projected into and out of all environments.

\section{Ensuring operational access and combat A2AD means}

In order to remain freedom of action and to be able to selectively use all elements of combat power, when needed and where needed, the great actors on the international scene act both to limit the opponent's access and freedom of action (A2AD measures), and to create the conditions for the insertion of forces into the operating area or to provide operational access, whether we are talking about a permissive, permeable environment, or we are talking about forcible entry force actions that include actions synergistically conducted simultaneously or successively by ground forces, "protected by joint air and missile defense, to achieve surprise and bypass or overcome enemy anti-access and area denial capabilities through intertheater and intratheater maneuver to multiple locations" [4].

As some states have developed A2AD capabilities and developed strategies specific to this domain, concerns have arisen in developing strategies to combat or limit the effects of A2AD. In this respect, specialists in the field focused on the issue of providing operational access and finding ways and means of countering A2AD.

Operational access can be achieved by integrating the capabilities of multi-domain forces, by exploiting the weaknesses of the defending opponent and selecting the most favorable entry points so as to achieve local superiority and create the conditions for fullfiling the objectives [5].

The measures aimed, on one hand at restricting the opponent's ability to perform actions in the A2AD spectrum and on the other hand creating optimal conditions for the insertion of troops into the operating area must be taken in the early phases of the 
planning process. Adopting and integrating these measures involves the creation of a multidimensional synergy, both strategically and tactically, in order to meet the challenges.

Ensuring operational access is a major challenge for any commander, because the success of the operation as a whole depends on the way it is accomplished. The high degree of risk associated with making operational access to areas controlled by the adversary or where its presence is significant, drastically limits commanders' choices, which must take into account the impact on troops, on how to achieve the objectives, the impact on public opinion, and to determine how to act, taking full advantage of troop capabilities and based on an impact-based approach. In order to prepare and conduct an operation in areas where the enemy has important A2AD capabilities, the specialists have concluded that a number of active and passive measures are needed to be implemented both in physical and cybernetic environments, whose main purpose is to limit the ability of the opponent to act in the A2AD field. Among those measures we can identify [6]:

- Conduct operations to gain access based on the requirements of the broader mission, while also designing subsequent operations to lessen access challenges.

- Prepare the operational area in advance to facilitate access, both informative and operational;

- Consider a variety of basing options, combining pre-deployed forces with rapid response forces designed to be airborne, naval or land-based, supported by special forces;

- Seize the initiative by deploying and operating on multiple, independent lines of operations, on multiple domains, with as many diversified forces as possible, to prevent the opponent from concentrating the elements of the fighting power at a single point;
- Exploit advantages in one or more domains to disrupt enemy antiaccess/area-denial capabilities in others, by combining actions in force, with those taking place in the media, diplomatic, psychological, physical or virtual environments;

- Disrupt enemy reconnaissance and surveillance efforts while protecting friendly efforts, by using modern technologies of interception, jamming, impairment of opponent's capabilities through actions originating from fixed or mobile platforms;

- Create pockets or corridors of local domain superiority to penetrate the enemy's defenses and maintain them as required to accomplish the mission, by timely concentration of effort;

- Maneuver directly against key operational objectives from strategic distance, with the use of means of discovery and long-distance engagement of targets, with high precision;

- Attack enemy antiaccess/area-denial defenses in depth rather than rolling back those defenses from the perimeter, to force the adversary to reconfigure their fighting formation and divide their forces;

- Maximize surprise through deception, stealth, and ambiguity to complicate enemy targeting due to the difficulty of discovering, prioritizing and effectively engaging targets;

- Protect space and cyber assets while attacking the enemy's space and cyber capabilities, in order to maintain the strategic advantage of controlling these specific, strategically important environments.

All these measures can also be taken at NATO level when considering an Article 5 operation, mainly because the forces are distributed in several countries, and the initial operations do not necessarily involve the full insertion of forces into the theater, with the lack of logistical support or combat support. Moreover, the geographic layout of 
NATO states offers multiple ways of access in most areas, both from land and using maritime platforms, such as the eastern flank of the Member States and the Black Sea and Baltic Sea, but also in the southern flank, using land forces from Turkey and maritime forces from Mediterranean Sea. Adoption of these measures does not mean neutralizing the opponent's A2AD measures and involves certain risks related to resource allocation, possible losses, cooperation between multinational forces and coordination of actions, etc. but it facilitates the action of forces in the early phases of the conflict.

\section{Russia's A2AD actions}

In recent years, Russia and China, two major regional powers with global ambitions, have begun to develop A2AD systems that would limit the freedom of action of NATO or US forces and regional allies. None of these states are large naval power, so most A2AD systems are mainly based on fixed or mobile terrestrial platforms, supplemented by aerial systems. The naval dimension of the A2AD measures is quite low, both due to the limited maritime power and the technological level. They have also begun to develop new maritime capabilities and to create and test new technologies. Thus, on the occasion of the Syrian war, Russia managed to test in real conditions certain weapon systems based on battle ships in the Caspian Sea, capable of striking long-range targets. These systems have been used against ground targets with limited efficiency, but can also be used in the application of the A2AD concept, and their testing in combat has made it possible to identify limitations and take corrective action. Developing specific capabilities and implementing measures in the A2AD field is not only a mean of defending against a potential aggressor but can also be an extremely effective offensive device if it is correlated with other weapon systems.

In this respect, we can support the idea that the development of Russia's A2AD capabilities and their disposition in NATO's areas of interest has not only a defensive role, especially as the essence of the Alliance is the defense of its members, but above all an offensive role, to limit NATO's ability to intervene effectively and decisively, in a short time, to defend the Member States located in the immediate vicinity of Russia such as the Baltic States, Poland, Romania and Bulgaria, taking into account the concentration of the main Russian systems in the Kaliningrad enclave, the Baltic Sea and the Black Sea, which limits NATO's ability to intervene in support of threatened allies.

The analysis of available data shows that Russia concentrates its A2AD systems in key areas such as Kaliningrad, the Baltic Sea, the Arctic, the Norwegian border, the Crimea area, the Moscow area, where longrange and medium range systems are deployed, as well as in northern Syria, where the Russians intended to create an air ban area targeting Turkish air force after the incident with the collapse of a Russian fighter plane.

The main means used for this purpose are the S 300, S 400, K 300 P Bastion antiaircraft missile systems, with ranges up to $400 \mathrm{~km}$, complemented by naval rocket systems such as SS-N-30, SS-N-26, with ranges up to $2500 \mathrm{~km}$, air combat systems, with modern weapons, radars and detection capabilities, submarines, etc. supported by means of electronic warfare, both ground and air based. Those capabilities represent only the major weapons systems available to russian forces and reprsent the core of the A2AD system.

The distribution of Russia's main A2AD means is shown in Figure no. 1, where we can see both their approximate location and range of action. From the analysis of the features and layout areas, we can see that Russia is trying to ensure control over areas of particular importance by deploying forces and means to cover the largest surface and to limit NATO's freedom of action. 


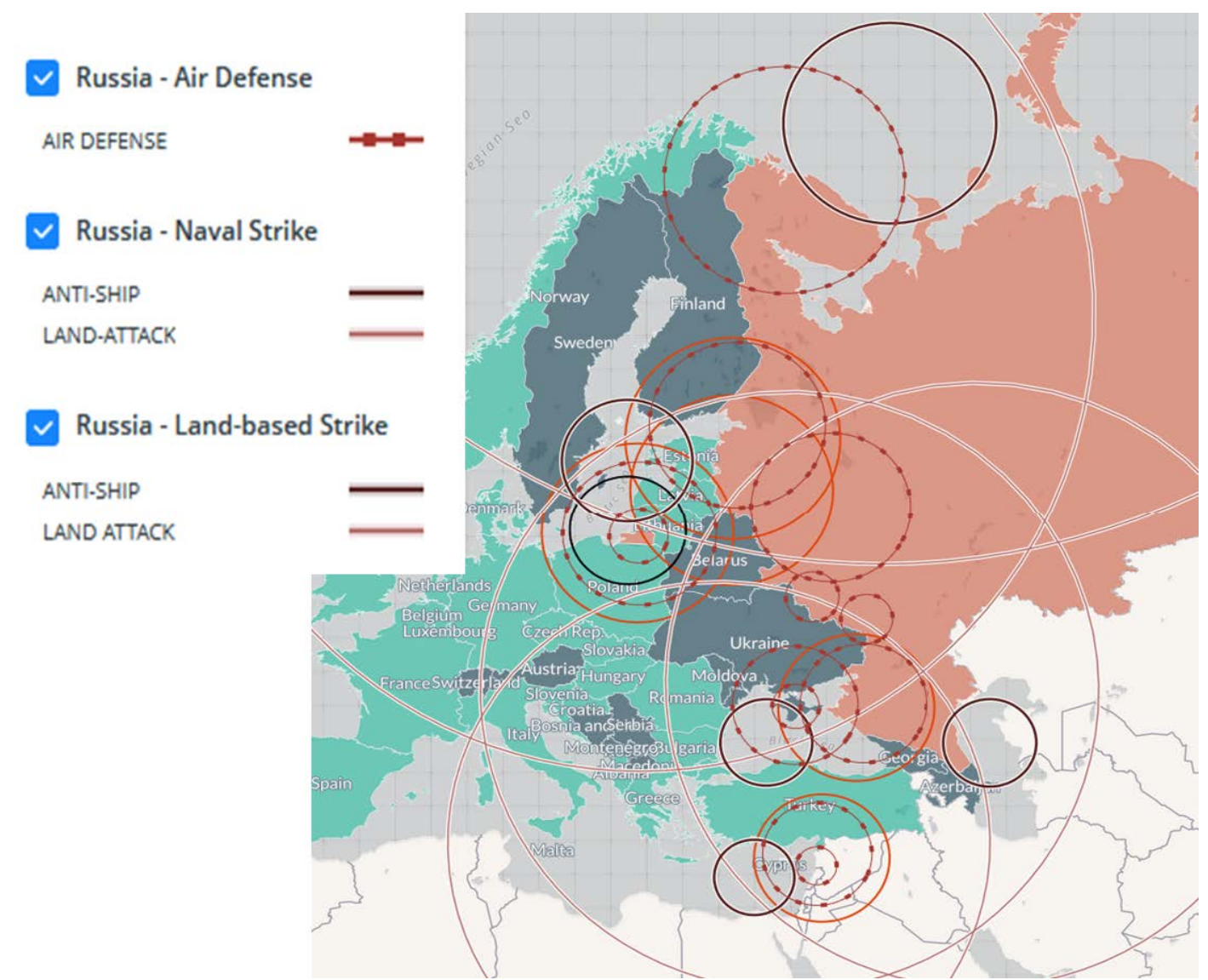

Figure 1: Russian A2AD capabilities [7]

At this moment, we consider that Russia has important A2AD capabilities that can be used to counter NATO actions in its border area, but in the absence of real possibilities to insert forces into conflict areas away from national territory and to support them for significant periods of time, it will not be able to exert a widespread influence as it would desire.

In order to counteract hostile actions in the A2AD field, NATO should focus on developing new capabilities and improving existing ones, so that in the event of conflict, they will be able to overcome these systems, either numerically or qualitatively. In order to reduce the number of victims in the first phases of an operation, it should be invested in misleading measures, in the development of false means, to use meteorological balloons or small drones that overwhelm the identification and target aquisition systems, create the impression of an attack, simulate real fighting means, etc., so that the system can not respond effectively, can not distinguish between false targets and real combat means, use special forces and means of high precision to neutralize the key points of the detection and target aquisition system, joint actions, simultaneously and successively across multiple points, to avoid concentrating effort. NATO has the human, technical and economic ability to overcome these A2AD systems designed by any other power. It is essential to create a unity of wills and a unity of action that will allow the optimal use of all available capabilities, including those in the cybernetic field, which must be further developed to have an offensive dimension as well. The unity of action must be sustained on all levels, including politically and diplomatically, and forces under a single command must act to reduce the opponent's ability to act, including small 
scale, with precise objective but important actions in different areas of the confrontation space, relying on obtaining and maintaining informational and decisional superiority.

In order to ensure the security of the allies in the eastern flank, NATO also deployed A2AD, especially Patriot systems and maritime-based systems, such as Tomahawk missile-carrying ships, aimed at discouraging hostile actions from Russia, but they are in a smaller number than Russia, which is in line with NATO's policy of deterring aggression, assuring allies, etc. These means, coupled with modern and efficient missile interceptor systems, such as Aegis embedded on maritime ships or ground systems, can limit the effectiveness of any opponent's A2AD measures.

\section{Conclusions}

The security environment is increasingly complex, and NATO needs to consider a wide range of threats. Since the 1990s, NATO has focused its attention on small-scale conflicts, mainly conducting stability and support actions, and less classic combat operations, which has influenced the organization, endowment and training of forces.

At the moment, NATO must continue to manage this type of low-intensity conflict, simultaneously with the reorientation towards the development of capabilities, plans, etc. targeting a possible mid or high intensity conflict against an opponent possessing A2AD capabilities that are duplicated or sustained by hybrids.

In order to overcome the A2AAD systems, it is necessary to conduct a complex operation, that allows to gain and maintain the initiative (forcible entry), a joint operation, integrating the capabilities of the forces "across multiple domains, exploiting gaps in an adversary's defenses at select entry points to achieve operational objectives" [7] and allowing for local superiority over a limited period of time in order to allow the consolidation of input forces, such as VJTF and NRF, and the access of subsequent forces to the operating area.

Knowing the opponent capabilities of the air defense and target detection and localization possibilities, knowing the locations of the fixed assets that can be used in A2AD actions, knowing the territory of the opponent and identifying possible locations for the use of mobile means, preparing plans for action on how to ensure freedom of action in areas considered strategic, in choke points etc. determine a favourable evolution of the events, so that the impact of the actions of a possible opponent is as small as possible. Essentially, these measures and actions are not new, they are applied in any conflict, it is different how the situation is to be assessed and the effects are calculated taking into account the evolution of technology and the increasing importance of the cybernetic dimension. The conduct of military action in an adversary-dominated A2AD environment is not new, but because the military and policy-makers' approach has changed, additional measures need to be taken to reduce the level of victims in the early stages of a conflict and to allow for a sufficient amount of force to be inserted as soon as possible in the conflict zone. In this respect, the synergic, multidimensional action of the forces is required and the optimal integration of all existing physical and cyber capabilities.

\section{References}

[1] Marius PRICOPI, Globalization of insecurity - a determining factor for the European defense integration, published at the 18-th International Scientific Conference „The Knowledge Based Organization”, Sibiu, June, 2012, "Nicolae Bălcescu" Land Forces Academy, p. 108, 2016. 
[2] Department of Defence, Joint Operational Acess Concept (JOAC), p. 6, 2012, accessed at http://www.dtic.mil/doctrine/concepts/joint_concepts/joac_2012.pdf.

[3] George M. Gross, The New Generation of Operational Concepts, p. 1, January 2016, in Small Wars Journal, accessed at http://smallwarsjournal.com/jrnl/art/the-new-generationof-operational-concepts.

[4] Department of the Army, The US Army operating concept - Win in a complex world 2020 - 2040, 31 october 2014, p. 6, accessed at http://www.tradoc.army.mil/tpubs/.

[5] Department of Defence, Joint operational access concept, 12 January 2012, p. ii, accessed https://www.defense.gov/Portals/1/Documents/pubs/JOAC_Jan\%202012_Signed.pdf;

[6] Department of Defence, Joint operational access concept, 12 January 2012, p. 17, accessed https://www.defense.gov/Portals/1/Documents/pubs/JOAC_Jan\%202012_Signed.pdf;

[7] Ian WILLIAMS, The Russia - NATO A2AD Environment, 3 January 2017, accessed at https://missilethreat.csis.org/russia-nato-a2ad-environment/

[8] Joint Chiefs of Staff, Joint concept for entry operations, 7 April 2014, p. vi, accessed at http://www.jcs.mil/Portals/36/Documents/Doctrine/concepts/jceo.pdf?ver=2017-12-28162000-837; 